\title{
Effects of Temperature on the Vigour of Motility, Oxygen Consumption and Duration of Motility of Fowl Spermatozoa under Aerobic Conditions
}

\author{
Koji Ashizawa and Hisayoshi Nishiyama \\ Laboratory of Animal Breeding, Faculty of Agriculture, \\ Kyushu University 46-06, Fukuoka-shi 812
}

It is generally considered that the vigour of motility and metabolic activity of mammalian spermatozoa increase with the rise in temperature and maximum metabolic activity of spermatozoa occurs at $40-47^{\circ} \mathrm{C}^{1-3)}$.

However, in fowl spermatozoa, it was reported that most types of synthetic diluents and oviducal juices preserved the vigour of motility at room temperature but inhibited it at about $41^{\circ} \mathrm{C}^{4}$. However, there have been few investigations concerned with the metabolism and survival of spermatozoa when the vigour of motility is inhibited at body temperature.

The present study was performed to investigate the relationship between the vigour of motility, oxygen consumption and duration of motility of spermatozoa in vitro at various temperatures.

\section{Materials and Methods}

White Leghorn roosters were used in this study. Semen was collected from several roosters by the method of Bogdonoff and ShaffNer ${ }^{5}$. The pooled semen was diluted with an appropriate volume of Ringer's solution $\left(8.6 \mathrm{~g} \mathrm{NaCl}, 0.3 \mathrm{~g} \mathrm{KCl}, 0.33 \mathrm{~g} \mathrm{CaCl}_{2}\right.$. $2 \mathrm{H}_{2} \mathrm{O} / 1,000 \mathrm{ml}, \mathrm{pH} 7.0$ ) and spermatozoa was washed once by centrifuging the suspension at $1,500 \mathrm{~g}$ for $10 \mathrm{~min}$. Washed spermatozoa were resuspended in Ringer's solution to give a concentration equivalent to that of undiluted semen. This semen was used as sample for the test.

Immediately after the sample was prepared, vigour of motility and oxygen consumption of spermatozoa were determined at various temperatures from 0.5 to $45^{\circ} \mathrm{C}$. The vigour of motility was assessed by the method described previously ${ }^{6}$ and scored by the 0 to 5 system $^{7}$. Oxygen consumption of spermatozoa was determined by the method of YAMADA and TERADA ${ }^{\left.{ }^{8}\right)}$ using a polarographic oxygen analyzer (Fieldlab, 39553 $\mathrm{O}_{2}$ sensor, Beckman Instruments Inc.). Sperm concentration was determined by the method of Salisbury et al. ${ }^{9}{ }^{\prime}$ with a spectrophotometer (Hitachi, Model 101), and the rate 
of oxygen consumption was expressed in terms of the $\mu l$ of $\mathrm{O}_{2}$ consumption $/ \mathrm{hr} / 10^{8}$ sperm.

To examine the duration of motility of spermatozoa at different tempratures, the semen samples were diluted 2 times with Ringer's solution and stored at various temperatures. The vigour of motility was assessed at $35^{\circ} \mathrm{C}$ until all spermatozoa lost their motility.

The statistical significance of the results was tested by the method of Duncan ${ }^{10}$.

\section{Results and Discussion}

The vigour of motility of spermatozoa increased with the rise in temperature and maximum motility was observed at 20 to $37^{\circ} \mathrm{C}$. At temperatures higher than $37^{\circ} \mathrm{C}$, the vigour of motility decreased rapidly and was greatly inhibited at $41-45^{\circ} \mathrm{C}$ (Table 1 ). These results were similar to those reported by $\mathrm{MUNRO}^{4)}$ and Ashizawa et $e l^{6}$.

The rate of oxygen consumption of spermatozoa increased with the rise in temperature until a peak at $37^{\circ} \mathrm{C}$ and then was depressed by about 40 per cent at $41-45^{\circ} \mathrm{C}$ (Table 1). While the vigour of motility of spermatozoa was almost inhibited at $5^{\circ} \mathrm{C}$ and $41^{\circ} \mathrm{C}$, the rate of oxygen consumption at $41^{\circ} \mathrm{C}$ was about 5.5 times higher than that at $5^{\circ} \mathrm{C}$. Therefore, it is possible to consider that the metabolic activity of spermatozoa increases with the rise in temperature regardless of their vigour of motility. On the other hand, the decrease in oxygen consumption at $41^{\circ} \mathrm{C}$ from its peak at $37^{\circ} \mathrm{C}$ was associated with a diminished vigour of motility of spermatozoa.

The duration of motility of spermatozoa decreased gradually with the rise in tem-

Table 1. Changes of vigour of motility, rate of oxygen consumption and duration of motility of fowl spermatozoa incubated in Ringer's solution at various temperatures under aerobic conditions

\begin{tabular}{cccc}
\hline Temperature $\left({ }^{\circ} \mathrm{C}\right)$ & $\begin{array}{c}\text { Vigour of } \\
\text { motility }\end{array}$ & $\begin{array}{c}\text { Rate of oxygen consumption } \\
\left(\mu l 0_{2} \text { consumption } / \mathrm{hr} / 10^{8} \text { sperm }\right)\end{array}$ & $\begin{array}{c}\text { Duration of } \\
\text { motility (days) }\end{array}$ \\
\hline 0.5 & $0-1$ & $0.152 \pm 0.017^{\mathrm{a}}$ & $6.0^{\mathrm{a} \prime}$ \\
5 & $0-1$ & $0.154 \pm 0.038^{\mathrm{a}}$ & $5.5^{\mathrm{a} \prime}$ \\
10 & $1-2$ & $0.198 \pm 0.025^{\mathrm{a}}$ & $5.0^{\mathrm{a} \mathrm{b}^{\prime}}$ \\
15 & $2-3$ & $0.257 \pm 0.031^{\mathrm{a}}$ & $4.0^{\mathrm{b} / \mathrm{c}^{\prime}}$ \\
20 & $4-5$ & $0.346 \pm 0.038^{\mathrm{a}}$ & $3.5^{\mathrm{c}^{\prime}}$ \\
25 & 5 & $0.571 \pm 0.039^{\mathrm{b}}$ & $2.1^{\mathrm{d}^{\prime}}$ \\
30 & 5 & $0.778 \pm 0.044^{\mathrm{bc}}$ & $0.8^{\mathrm{e}^{\prime}}$ \\
35 & 5 & $1.139 \pm 0.031^{\mathrm{d}}$ & $0.7^{\mathrm{e}^{\prime}}$ \\
37 & $4-5$ & $1.373 \pm 0.076^{\mathrm{e}}$ & $0.6^{\mathrm{e}^{\prime}}$ \\
39 & $1-2$ & $1.108 \pm 0.133^{\mathrm{d}}$ & $0.5^{\mathrm{e}}$ \\
41 & $0-1$ & $0.831 \pm 0.042^{\mathrm{c}}$ & $0.5^{\mathrm{e}}$ \\
45 & $0-1$ & $0.812 \pm 0.045^{\mathrm{c}}$ & $0.3^{\mathrm{e}^{\prime}}$ \\
\hline
\end{tabular}

Vigour of motility and oxygen consumption of spermatozoa were determined immediately after the semen samples were prepared. Each value of the rate of oxygen consumption represents an average of 6 trials $\pm \mathrm{S}$. E. M. Duration of motility was assessed by storing the semen samples in vitro and each value represents an average of 6 trials. Within columns, values with different superscripts differ significantly $(\mathrm{P}<0.01)$ from each other. 
perature and no prolongation of it due to the inhibited motility of spermatozoa was observed at high temperature ranges. The duration of motility was within 1 day at temperatures higher than $30^{\circ} \mathrm{C}$ (Table 1 ).

It is interesting to speculate about the relevance of the observations in this study to the survival of spermatozoa in the oviduct of the female bird. The conditions existing in the hen's oviduct are compatible with the aerobic metabolism of spermatozoa ${ }^{11}$ and Nevo and SchINDLER ${ }^{12}$ ) consider that the glandular portion of sperm-host glands is well supplied with blood vessels, making aerobic metabolism of spermatozoa possible. On the other hand, MUNRO ${ }^{4}$ demonstrated that fowl spermatozoa lost their vigour of motility at body temperature in oviducal juices. Therefore, it is assumed that spermatozoa are stored quiescently in the sperm-host glands under aerobic conditions.

Our observations showed that the duration of motility of spermatozoa was not prolonged at $41^{\circ} \mathrm{C}$ in vitro, but it was assumed that the lack of motility and a lower metabolic activity of spermatozoa stored in the glands might be useful for their prolonged survival.

\section{Summary}

Fowl spermatozoa were incubated in Ringer's solution at various temperatures under aerobic conditions.

Maximum motility of spermatozoa was observed at a temperature ranging between 20 and $37^{\circ} \mathrm{C}$, while the vigour of motility was greatly inhibited at between $0.5-5^{\circ} \mathrm{C}$ and $41-45^{\circ} \mathrm{C}$. Oxygen consumption of spermatozoa increased with the rise in temperature until a peak at $37^{\circ} \mathrm{C}$ and then was depressed by about 40 per cent at $41-45^{\circ} \mathrm{C}$. The duration of motility of spermatozoa decreased progressively with the rise in temperature.

\section{Acknowledgement}

We would like to thank Mr. K. Shibuta for his technical assistance. This study was supported by a grant from the Ministry of Education of Japan (156185).

\section{References}

1) Beck, G. H. and G. W. Salisbury: J. Dairy Sci., 26, 483, 1943.

2) Freund, M., J.P. Mixner and R.E. Mather: J. Dairy Sci., 42, 79, 1959.

3) Salisbury, G. W. and J.R. Lodge: Adv. Enzymol., 24, 35, 1962.

4) Munro, S.S.: Q. J. exp. Physiol., 27, 281, 1938.

5) Bogdonoff, P.D., Jr and C.S. Shaffner: Poultry Sci., 33, 665, 1954.

6) Ashizawa, K., H. Nishiyama and T. Nagae: J. Reprod. Fert., 47, 305, 1976.

7) Wheeler, N. C. and F. N. Andrews: Poultry Sci., 22, 361, 1943.

8) Yamada, M. and T. Terada: Am. J. Physiol., 227, 729, 1974.

9) Salisbury, G. W., G. H. Beck, I. Elliott and E.L. Willett: J. Dairy Sci., 26, 69, 1943.

10) Duncan, D. B.: Biometrics, 11, 1, 1955.

11) Lehrer, A.R. and H. Schindler: Poultry Sci., 48, 30, 1969.

12) Nevo, A.C. and H. Schindler: VI Cong. Intern. Reprod. Anim. Insem. Artif., Paris, Vol. II, 1637, 1968. 